\title{
DOENÇA DE CHAGAS: PRIMEIROS CASOS AUTÓCTONES NO ESTADO DO PIAUI *
}

\author{
Paulo Zábulon de Figueirêdo,"* Fernando Gomes Correia Lima *** e José Nathan \\ Portella Nunes ***
}

Os Autores fazem a apresentação dos primeiros casos autóctones da Doença de Chagas no Estado do Piauí. Referem-se, ainda, à captura de triatomineos em alguns municípios do Estado e chamam a atenção para a infecção natural de alguns desses espécimes capturados.

\section{INTRODUÇÃO}

A Doença de Chagas tem sido assinalada em quase todos cs Estados brasileiros. Nas regiões sul e centro do país, já foi diagnosticada no Rio Grande do Sul, Santa Catarina, São Paulo, Rio de Janeiro, Espírito Santo, Minas Gerais e Goiás (5) além do Paraná por Queiroz \& Pascual (7) e Pessoa (5) .

Na região nordeste, a Doença de Chagas estende-se pelos Estados da Bahia, (5); Alagoas, segundo Lucena \& cols. (2); Pernambuco, (4); Paraíba, por Silva \& cols. (9); Rio Grande do Norte, descrito por Lucena \& cols. (3) e Ceará (1).

$\mathrm{Na}$ região norte, Lainson \& cols. citam os primeiros casos autóctones na cidade de Belém do Pará apud Pessoa \& Martins, (6) .

No Estado do Piaui, nenhuma referência existe scbre essa endemia, mesmo tendo-se conhecimento da existência de triatomíneos na região. A inexistência de publicações sobre a Doença de Chagas neste Estado deve-se mais à falta de pesquisa do que mesmo à ausência da endemia.
Com relação a sua transmissão no Piauí, pode-se informar a existência de triatomíneos (Triatoma brasiliensis, $T$. maculata e $T$. sordida), por nós capturados em alguns municípios do Estado encontrados em grande quantidade, quer no interior de domicílios ou fora destes (como galinheiros, principalmente). É válido salientar que alguns desses espécimes capturados estavam infectados por um Trypanosoma semelhante ao "cruzi", fazendo - nos crer serem esses "barbeiros" responsáveis pelos casos da infecção chagásica já diagnosticados por nós em vinte e dois municípios do Estado do Piauí.

\section{CASUÍSTICA}

CASO 1 - A.R.S., 15 anos, feminina, parda, natural cie ceiras - Piauí, nunca se afastou do Estado. Internada em .... 17/9/74 na Clínica Médica do Hospital Getúlio Vargas, em Teresina, apresentou queixa de disfagia progressiva há três anos. Relatava dificuldade na deglutição, inicialmente para sólidos, evvoluindo para ali-

* Trabalho realizado nas Disciplinas de Parasitologia Médica e Doenças Infecto-Contagiosas e Parasitárias do Departamento de Medicina Comunitária do Centro de Ciências da Saúde da UFPi.

* Professor da Disciplina de Parasitologia Médica.

*** Professores da Disciplina de Doenças Infecto-Contagiosas e Parasitárłas. Recebido para publicação em 18-3-75. 
mentos pastosos. Mora em casa de "adobo" sem reboco e con'hece o "barbeiro".

Exame físico - Estado geral bom. Pele e mucosas levemente descoradas, não apresentando outras alteraçōes. PA $120 \mathrm{x}$ $80 \mathrm{mmHg}$; PR $80 \mathrm{bpm}$; TA $36,4^{\circ} \mathrm{C}$.

Exames complementares - Raio $\mathrm{X}$ de esôfago contrastado revelou mega grau II. Eletrocardiograma normal. Sorologia (Imunofluorescência indireta e Guerreiro-Machado) positiva. Xenodiagnóstico positivo.

Encaminhada à Clínica Cirúrgica, foi submetida a operações de Heller-Nissen, recebendo alta $\mathrm{em}$ boas condições.

CASO 2 - J.L.B.F., 36 anos, masculino, pardo, lavrador, natural de Castelo Piaui, nunca se afastou do Estado. Internado em 26/07/74 na Clínica Médica do Hospital Getúlio Vargas, em Teresina, informou que há oito meses apresentou dispnéia progressiva e edema de membros inferiores. Relatou dor epigástrica e palpitaçōes freqüentes.

Exame físico - Estado geral precário. Pele e mucosas descoradas, dispnéia e anasarca. Extrassístoles freqüentes. PA $100 \mathrm{x}$ $70 \mathrm{mmHg}$; PR $79 \mathrm{bpm}$; TA 36,0 $0^{\circ}$.

Exames complementares - Eletrocardiograma revelou BAV $10^{\circ}$ grau, extrassístoles ventriculares freqüentes, sobrecarga esquerda e alteração na repolarização ventricular. Raio $\mathrm{X}$ de tórax mostrando aumento global da área cardíaca. Sorologia (Imunofluorescência indireta e Guerreiro-Machado) positiva. Xenodiagnóstico positivo.

O paciente, compensado clinicamente, recebeu alta em condições melhoradas.
CASO 3 - A. C., 48 anos, feminina, branca, doméstica, viúva, natural de Bom Jesus do Gurguéia - Piauí. Procurou os serviços médicos, queixando-se de dispnéia e palpitações. Refere-se, ainda, à cefaléia ocasional, edema de membros inferiores e constipação intestinal.

Exame físico - Estado geral bom, com deambulação prejudicada. PA $130 \times 60$ $\mathrm{mmHg}$; PR $34 \mathrm{bpm}$; TA $36,4^{\circ} \mathrm{C}$. A ausculta cardiaca mostrava um ritmo regular de 2 tempos com bradicardia intensa. O exame neurológico mostrou paraplegia espasmódica e distúrbios esfincterianos.

Exames complementares - Eletrocardiograma revelou BAV completo, bloqueio $R D$, extrassístoles multifocais e alteração da repolarização ventricular. Sorologia (Imunofluorescência indireta e Guerreiro-Machado) positiva. Xenodiagnóstico positivo.

\section{COMENTÁRIOS E CONCLUSÁO}

Tendo em vista os três casos apresentados em que se verificaram, além de sinais clínicos da Doença de Chagas;

- a confirmação diagnóstica através de exames complementares (eletrocardiograma, raio $\mathbf{X}$, Imunofluorescência indireta e Guerreiro-Machado); sitiva; $\mathbf{e}$

- a pesquisa parasitológica (xenos) po-

- a presença de triatomineos no Estado ( alguns deles naturalmente infectados;, pode-se afirmar, de maneira inconteste, a existência de mais essa endemia, enfileirando o quadro nosológico do Estado do Piauí.

The authors present the first authoctonous cases of Chagas' disease the State of Piaui. They refer to the capture of triatomine buys in some communities in the State and point out the natural infection of some captured species. 
1. ALENCAR, J.E., FONTENELE, Z.F., CUNHA, R.V. \& SHERLOCK, I.R.A. - A Moléstia de Chagas no Ceará. An. Cong. Intern. Doen. Chagas, 1: 35-50, 1959 .

2. LUCENA, D.T., ROSA D. \& CALHEIROS, J.N. - Epidemiologia da Doença de Chagas em Alagoas. Rev. Bras. Medicina, 18: 258-261, 1961.

3. LUCENA, D.T. \& LIMA, C.T. - Epidemiologia da Doença de Chagas no Rio Grande do Norte. III - A Infecção Humana Determinada pela Reação de Guerreiro-Machado. Rev. Bras. Malariol. Doen. Trop., 15: 361-366, 1962.

4. MARQUES, R.J. - Alguns Aspectos da Doença de Chagas em Pernambuco. Tese, Faculdade de Medicina do Recife, 1955 .

5. PESSOA, S.B. - Parasitologia Médica. 8a ed. Edit. Guanabara Koogan, Rio de Janeiro, 1972.
6. PESSOA, S.B. \& MARTINS, A.V. -Parasitologia Médica. 9ạ ed. Edit. Guanabara Koogan, Rio de Janeiro, 1974.

7. QUEIROZ, J.A. \& PASCUAL, J. Contribuição ao Estudo da Doença de Chagas no Norte do Paraná. Rev. Med. Paraná, 27: 27-30, 1959.

8. SANTOS, U.M., PINTO, A.F.S., LUIZ ZAGANEILI, F., ZÉLIO ALMEIDA, A., MARTINS, A, VIEIRA CARANCHO, $\mathbf{P}$. \& VIEIRA, H.J. - Doença de Chagas no Estado do Espírito Santo. II - Inquérito Sorológico. Rev. Soc. Bras. Mea. Trop., 3: 51, 1969.

9. SILVA, L.H.P., CARVALHO, S.B. \& CARNEIRO, N.N.R. - Doença de Chagas na Paraíba. Inquérito sorológico preliminar. Rev. Bras. Malariol. e Doen. Trop., 8: 281-288, 1956. 